\title{
Saroglitazar improved hepatic steatosis and fibrosis by modulating inflammatory cytokines and adiponectin in an animal model of non-alcoholic steatohepatitis
}

Rasoul Akbari ${ }^{1,2}$, Tahereh Behdarvand ${ }^{1,2}$, Reza Afarin ${ }^{1,2}$, Hamid Yaghooti ${ }^{1}$, Mohammad Taha Jalali ${ }^{1,2}$ and Narges Mohammadtaghvaei ${ }^{1,2^{*}}$

\begin{abstract}
Background: Non-alcoholic fatty liver disease (NAFLD) and non-alcoholic steatohepatitis (NASH) have become significant global health concerns. In the present study, we aimed to investigate the effects of saroglitazar, a dual PPARa/ $/$ agonist, fenofibrate, a PPAR-a agonist, and pioglitazone, a PPAR- $\gamma$ agonist on an animal model of NASH.

Methods: Male Wistar rats were fed a high-fat (HF) emulsion via gavage for 7 weeks to induce NASH. The HFtreated rats were grouped into four groups to receive saroglitazar, pioglitazone, fenofibrate, or vehicle. We measured body and liver weight, liver enzymes, serum levels of adiponectin and leptin. We also performed histopathological examinations and gene expression analysis of interleukin 6 (IL-6), tumor necrosis factor-alpha (TNF- $a$ ), transforming growth factor-beta (TGF- $\beta$ ), and monocyte chemoattractant protein 1 (MCP-1).

Results: Body weight was markedly normalized by both saroglitazar and fenofibrate, while the liver index only decreased significantly with saroglitazar. Saroglitazar corrected ALT, AST, leptin, and adiponectin levels better than pioglitazone and fenofibrate. All PPAR agonists significantly attenuated the upregulation of the proinflammatory and TGF- $\beta$ genes, which correlated with the improved steatosis, inflammation of liver tissue, and fibrotic lesions.

Conclusions: As documented by our results, the dual activation of PPARa/Y by saroglitazar could effectively improve steatosis, fibrosis, and aspects of necro-inflammation in the HF-induced NASH model more than fenofibrate and pioglitazone, and it can be more beneficial in the management of NASH.
\end{abstract}

Keywords: Saroglitazar, NASH, PPAR- $a / \gamma$, TNF- $a$, TGF- $\beta$, MCP-1, IL-6

\section{Background}

Non-alcoholic fatty liver disease (NAFLD), a metabolic liver disorder, is globally the most common liver disease. Progression to its dangerous form, non-alcoholic steatohepatitis (NASH), is becoming increasingly prevalent [1].

\footnotetext{
* Correspondence: ntaghvaie@gmail.com

${ }^{1}$ Hyperlipidemia Research Center, Ahvaz Jundishapur University of Medical Sciences, Ahvaz, Iran

${ }^{2}$ Department of Laboratory Sciences, School of Allied Medical Sciences, Ahvaz Jundishapur University of Medical Sciences, Ahvaz, Iran
}

Hepatic steatosis in NAFLD is characterized by a considerable accumulation of fat droplets within hepatocytes. Consequent hepatic inflammation and hepatocellular injury with or without hepatic fibrosis lead to the advanced stages of the disease termed NASH. According to the multi-hit hypothesis, multiple factors predispose to the development of NAFLD and NASH [2]. Among them, inflammation, oxidative stress, endoplasmic reticulum stress, altered lipid metabolism, insulin resistance, altered production of adipokines and cytokines

(c) The Author(s). 2021 Open Access This article is licensed under a Creative Commons Attribution 4.0 International License, which permits use, sharing, adaptation, distribution and reproduction in any medium or format, as long as you give appropriate credit to the original author(s) and the source, provide a link to the Creative Commons licence, and indicate if changes were made. The images or other third party material in this article are included in the article's Creative Commons licence, unless indicated otherwise in a credit line to the material. If material is not included in the article's Creative Commons licence and your intended use is not permitted by statutory regulation or exceeds the permitted use, you will need to obtain permission directly from the copyright holder. To view a copy of this licence, visit http://creativecommons.org/licenses/by/4.0/ The Creative Commons Public Domain Dedication waiver (http://creativecommons.org/publicdomain/zero/1.0/) applies to the data made available in this article, unless otherwise stated in a credit line to the data. 
have prominent roles in the disease [2-4]. It is well established that adipose tissue plays a pivotal role in developing NASH through the secretion of adipokines such as leptin, adiponectin, and inflammatory cytokines [5]. Adipose tissue expansion disturbs the balance between leptin and adiponectin by decreasing adiponectin and increasing leptin, leading to obesity, insulin resistance, and hepatic steatosis [5-7]. Tumor necrosis factor (TNF)- $\alpha$ is a proinflammatory cytokine secreted by adipose tissue, hepatocytes, and Kupffer cells in the liver. It plays an essential role in developing hepatic steatosis and mediates hepatic inflammation, oxidative stress, and apoptosis or necrosis of hepatocytes $[8,9]$. Monocyte chemotactic protein-1 (MCP-1), transforming growth factor (TGF)- $\beta$, and interleukin-6 (IL-6) are proinflammatory cytokines produced by resident macrophages in hepatocytes, which are dependent on TNF- $\alpha$ acting as an upstream mediator $[10,11]$. TGF- $\beta 1$ is the main liver isoform that plays a critical role in hepatic fibrosis by mediating the activation of stellate cells and their production of extracellular matrix proteins [12, 13]. Also, MCP-1 is a potent chemokine mainly secreted by macrophages and hepatic stellate cells [14]. MCP-1, through multiple mechanisms, contributes to the pathogenesis of NASH, including hepatic lipid accumulation, insulin resistance, and coordinates leukocyte recruitment to the liver [15]. The role of IL-6 in the liver is very complex. IL-6 sensitize the liver to injury, stimulate hepatocyte apoptosis, induce insulin resistance, and participates in NASH development [13].

Peroxisome proliferator-activated receptor alpha/ gamma (PPAR $\alpha / \gamma)$ receptors modulate glucose and lipid metabolism in the liver, adipose tissues, and muscles. PPAR $\alpha / \gamma$ dual agonists have shown good potentials to treat metabolic diseases [16]. The activation of PPAR $\alpha$ stimulates fat consumption by inducing the expression of genes associated with beta-oxidation, resulting in improved hyperlipidemia. PPAR $\gamma$, on the other hand, promotes the mobilization of fatty acid into adipocytes by encouraging adipogenesis and upregulating the expression of genes involved in fatty acid transport [17]. In addition, activation of PPAR $\alpha$ increases adiponectin receptors in the adipose tissue and decreases MCP-1 expression in adipose tissue and macrophages [18]. Since PPARy agonists induce storage of fatty acids and glucose rather than consumption in the cell, the dual activation of PPAR $\alpha$ and PPAR $\gamma$ is proposed to be more beneficial in managing metabolic diseases such as dyslipidemia of diabetes and fatty liver.

In the present study, we investigated the comparative effects of saroglitazar (SARO), a dual PPAR $\alpha / \gamma$ agonist, versus fenofibrate (FENO) and pioglitazone (PIO) as separate $\alpha$ and $\gamma$ agonist on the adipose tissue factors and inflammatory components of NASH, developed in rats using a high-fat formulation.

\section{Materials and methods \\ Preparation of the high-fat emulsion}

The composition of the high-fat emulsion used to induce NASH is shown in Table 1 . It provided $77 \%$ of its energy from fat, $9 \%$ from carbohydrates, and 14\% from whole milk powder as a source of protein. We prepared the high-fat emulsion as described by Yuhong Zou et al. [19]. This emulsion was stored at $4{ }^{\circ} \mathrm{C}$ and was thoroughly mixed and heated in a $42^{\circ} \mathrm{C}$ water bath daily before use.

\section{Chemicals}

Saroglitazar was supplied by Cadila Healthcare Limited, Ahmedabad, India. Both fenofibrate and pioglitazone were purchased from the Abidi Pharmaceutical Company, Tehran, Iran. The drugs were suspended in $0.5 \%$ sodium carboxymethyl cellulose solution (CMC) for administration.

\section{Animals and experimental design}

Adult male Wistar rats, weighing 180-200 g, were purchased from the Experimental Animal Center, Ahvaz Jundishapur University of Medical Sciences, and were quarantined for 1 week before the experiments started. Animals were kept in comfortable cages under controlled environmental conditions at a room temperature of $25 \pm 3{ }^{\circ} \mathrm{C}$ with $55 \pm 8 \%$ humidity under 12 -h light-dark cycles. All experiments on laboratory animals were approved by the University Ethics Committee and performed according to the regulations for using and caring for experimental animals at Ahvaz Jundishapur University of Medical Sciences.

Table 1 The composition of macronutrients and caloric content of the high-fat emulsion

\begin{tabular}{ll}
\hline Components of high fat emulsion & Amount \\
\hline Corn oil (g) & 400 \\
Saccharose (g) & 150 \\
Total milk powder (g) & 80 \\
Cholesterol (g) & 100 \\
Sodium deoxycholate (g) & 10 \\
Tween $80(\mathrm{~g})$ & 36.4 \\
Propylene glycol (g) & 31.1 \\
Vitamin mixture (g) & 2.5 \\
Cooking salt (g) & 10 \\
Mineral mixture (g) & 1.5 \\
Distilled water (ml) & 300 \\
Total energy (kcal/l) & 4342 \\
\hline
\end{tabular}


At first, 45 rats were randomly divided into two groups: the normal control $(\mathrm{NC})$ group $(n=9)$ and the high-fat emulsion (HF) group $(n=36)$. The standard diet and water were available to all animals during the study. Rats in the high-fat emulsion group were orally given the high-fat emulsion $(10 \mathrm{ml} / \mathrm{kg})$ daily via gavage for 7 weeks. Additionally, they were allowed free access to drinking water containing $18 \%$ saccharose to induce a more characteristic NASH. During the seventh week, to ensure the development of NAFLD/NASH, two NC and four HF group rats were randomly sacrificed. Their livers were sent to our laboratory for pathological examinations. After confirming the successful model, pharmacological treatments were carried out separately from the 8th week for 6 weeks. For this purpose, animals in the HF group were randomly divided into groups I to IV (using a random number table) as follow; Group I: control $\mathrm{HF}$ that received equal volumes of $0.5 \% \mathrm{CMC}$ solution (drug vehicle), II: high-fat emulsion plus fenofibrate $100 \mathrm{mg} / \mathrm{kg}$ body weight (HF + FENO group), III: high-fat emulsion plus pioglitazone $30 \mathrm{mg} / \mathrm{kg}$ body weight $(\mathrm{HF}+$ PIO group), IV:high-fat emulsion plus Saroglitazar $3 \mathrm{mg} /$ $\mathrm{kg}$ body weight (HF + SARO group). After a high dose ketamine-xylazine injection at the end of treatments, we sacrificed $15 \mathrm{~h}$ fasting rats. Blood samples were drawn from the aorta ventralis. After dissecting the livers, they were washed with normal cold saline and dried on sterile filter papers. They were immediately weighed to calculate liver index (liver weight/body weight $\times 100$ ). Each liver was cut into pieces, and aliquots of the liver tissue were snap-frozen in liquid nitrogen at $-180{ }^{\circ} \mathrm{C}$ for further gene expression analysis. A larger piece of liver was immersed in a $10 \%$ formalin solution for histopathological examination.

\section{Biochemical measurements}

Levels of liver enzymes in serum, including alanine aminotransferase (ALT) and aspartate aminotransferase (AST), were measured using corresponding assay kits by the Roche 6000 auto-analyzer. Leptin and adiponectin concentrations were determined using enzyme-linked immunoassay kits (DRG Diagnostics, Marburg, Germany).

\section{Gene expression analysis}

Gene expression of IL- 6 , TNF- $\alpha$, TGF- $\beta$, and MCP-1 was evaluated by real-time PCR technique. For this purpose, total RNA was isolated from the frozen liver samples with the FastPure ${ }^{\mathrm{is}}$ RNA Kit from Takara Bio (Otsu, Japan) according to the manufacturer's protocol. The reverse transcription was performed using PrimeScript RT reagent Kit (Takara Bio, Otsu, Japan). Real-time PCR was carried out using SYBR Green Premix Ex $\mathrm{Taq}^{\mathrm{Tm}}$ mix (Takara Bio, Otsu, Japan) and QuantStudio ${ }^{\text {тм }} 3$ Real-
Time PCR System (ABI Applied Biosystems). The expression level of the target mRNA was normalized against $\beta$-actin expression as an internal standard. At the end of the real-time PCR procedure, relative quantification was performed with the Applied Biosystem software. The primer sequences used for the real-time PCR reactions are shown in Table 2.

\section{Histopathological evaluations}

Pieces of liver tissue were removed from the formalin solution, and following dehydration with gradient alcohol, they were embedded in paraffin wax. Sections of 6$7 \mu \mathrm{m}$ thickness were cut and stained with hematoxylineosin (HE) and Masson's trichrome in two parts to investigate hepatic steatosis, inflammation, necrosis, and fibrosis. Histopathological changes were evaluated by an experienced liver pathologist who was blind to the interventions. The severity of steatosis, inflammation and fibrosis were scored and graded according to the NASH activity score (NAS), described by Kleiner, D. E, et al. and Liang, W, et al. [20, 21].

\section{Statistical analysis}

The data were statistically analyzed with the one-way analysis of variance (ANOVA) followed by Tukey's post hoc test for multiple comparisons using GraphPad Prism version 8.0.2 for Windows (GraphPad Software, La Jolla, CA, USA). Results were considered significant at $P$-value $<0.05$.

\section{Results}

Changes in body weight and liver index in response to treatments

As shown in Fig. 1, A, there were no significant differences in body weights at the beginning of the experiment. Rats fed with the high-fat emulsion for 13 weeks showed significantly increased body weight $(p<0.001)$, liver weight $(p<0.001)$, and liver index $(p<0.01)$ in comparison to the NC group. After the next 6 weeks of treatment, the increase in body weight was markedly normalized by both saroglitazar and fenofibrate $(p<0.01)$. In contrast, treatment with pioglitazone did not correct the body weight compared to the HF group. Also, treatment with saroglitazar and pioglitazone significantly reduced the liver weight compared to the HF group ( $p<0.01$ and $p<0.05$, respectively, Fig. 1B). Figure $1 \mathrm{C}$ shows that saroglitazar treatment for 6 weeks decreased liver index by $17 \%$ compared to the HF group $(p<0.05)$. In contrast, treatment with fenofibrate increased liver index, but the increase was not statistically significant. 
Table 2 Primer pairs sequences

\begin{tabular}{|c|c|c|}
\hline Gene & Forward primer & Reverse primer \\
\hline TNF- $a$ & 5'-ACCACGCTCTTCTGTCTACTG-3' & 5'-CTTGGTGGTTTGCTACGAC-3' \\
\hline IL- 6 & 5'- TGATGGATGCTTCCAAACTG-3' & 5'- GAGCATTGGAAGTTG GGGTA-3' \\
\hline TGF- $\beta$ & 5'-CAAAGACATCACACACAGTA-3' & 5'-GGTGTTGAGCCCTITCCAGG-3' \\
\hline MCP1 & 5'-GTGCTGACCCCAATAAGGAA -3' & 5'-TGAGGTGGTTGTGGAAAAGA-3' \\
\hline$\beta$-Actin & 5'-CCCATCTATGAGGGTTACGC-3' & 5'-TTTAATGTCACGCACGATTTC-3' \\
\hline
\end{tabular}

\section{Saroglitazar corrected the elevated liver enzymes and adipokines in the NASH model}

ALT and AST as biomarkers of liver injury were measurements in this study. Feeding rats with the high-fat emulsion led to marked elevations in ALT and AST levels in serum compared to the rats in the NC group $(p<0.001$, Table 3$)$. The PPAR agonists differentially reversed the injurious effect of high-fat emulsion and decreased ALT and AST to different levels $(p<0.05)$. Saroglitazar showed better efficacy in reducing and normalizing ALT and AST levels than pioglitazone and fenofibrate.
As shown in Table 3, feeding rats with the high-fat emulsion caused an almost 2.1-fold increase in leptin level and a 3.6-fold decrease in adiponectin level in serum compared to those in the $\mathrm{NC}$ group. All drugs successfully reversed the increase in leptin level (SARO; $p<0.001$, FENO; $p<0.05$, PIO; $p<0.01)$. Also, treatment with saroglitazar $(p<0.001)$, fenofibrate $(p<0.001)$ and, pioglitazone $(p<0.05)$ significantly enhanced adiponectin level as compared to the HF group. Saroglitazar showed a higher effect on correcting the levels of adipokines.

A

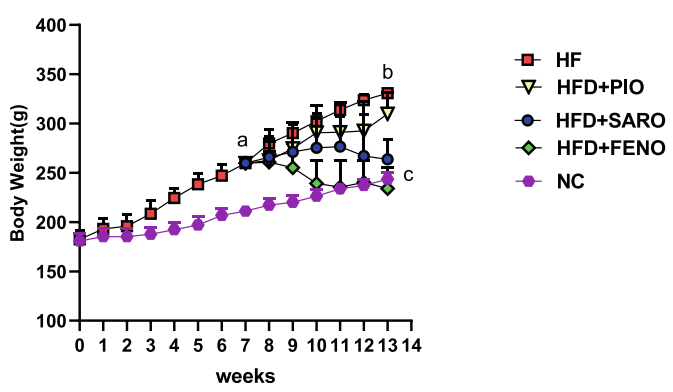

B

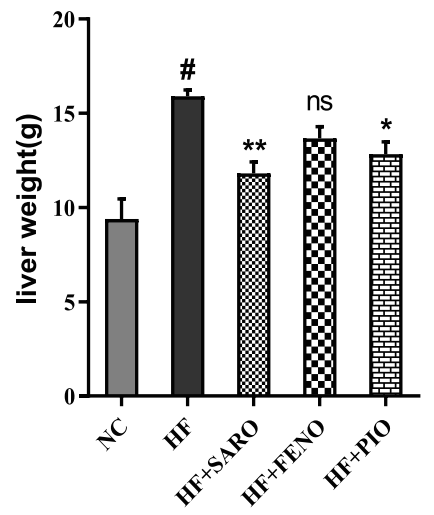

C

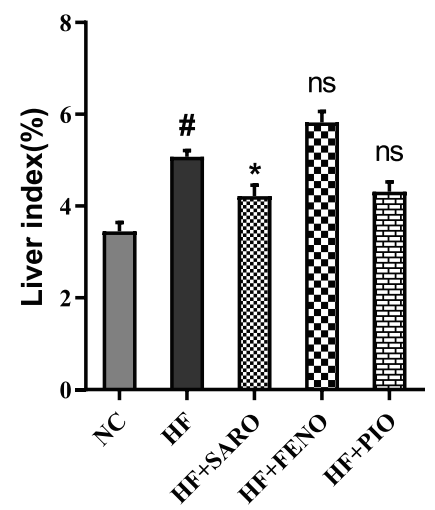

Fig. 1 Effect of saroglitazar, fenofibrate, and pioglitazone on the body weight (A), liver weight (B), and percentage of the liver index (C) in the HFinduced NASH model. Values are expressed as mean $\pm \mathrm{SD}(n=7)$. NC = normal control, $\mathrm{HF}=$ high-fat emulsion, $\mathrm{SARO}=\mathrm{Sarog}$ litazar, $\mathrm{FENO}=$ Fenofibrate, $\mathrm{PIO}=$ Pioglitazone. $\mathbf{a}$ and $\mathbf{b}$ indicate Significant difference against NC after 7 and 13 weeks, $\mathbf{c}$ indicates significant differences between $\mathrm{NC}, \mathrm{HF}+\mathrm{SARO}$, and HF + FENO vs. HF, $p<0.001 .{ }^{*} p<0.05$; ${ }^{* *} p<0.01$; and ns (nonsignificant) vs HF. \# indicates significance vs. NC, $p<0.001$ 
Table 3 Biochemical parameters of rats in different groups

\begin{tabular}{llllll}
\hline Parameters & NC & HF & HF + SARO & HF + FENO & HF + PIO \\
\hline ALT (IU/l) & $33.47 \pm 4.93$ & $69.12 \pm 7.33 \#$ & $37.81 \pm 4.51 * * *$ & $53.26 \pm 8.61^{* *}$ & $51.48 \pm 9.71^{* *}$ \\
AST (IU/l) & $42.29 \pm 4.15$ & $103.91 \pm 16.75 \#$ & $39.08 \pm 12.56^{* * *}$ & $66.21 \pm 5.01^{* * *}$ & $84.73 \pm 5.37 *$ \\
Leptin $(\mathrm{ng} / \mathrm{ml})$ & $1.41 \pm 0.23$ & $3.12 \pm 0.65 \#$ & $1.86 \pm 0.53 * * *$ & $2.37 \pm 0.41^{*}$ & $2.19 \pm 0.31^{* *}$ \\
Adiponectin $(\mathrm{mg} / \mathrm{ml})$ & $5.61 \pm 0.78$ & $1.55 \pm 0.46 \#$ & $4.70 \pm 0.99 * * *$ & $3.95 \pm 0.83 * * *$ & $3.39 \pm 1.03 *$ \\
\hline
\end{tabular}

Values are expressed as the mean \pm S.D. of 7 rats. Between group comparisons was tested by ANOVA followed by Tukey Kramer multiple comparisons test. NC normal control, HF high-fat emulsion, SARO Saroglitazar, FENO Fenofibrate, PIO Pioglitazone. $p<0.05 ;{ }^{* *} p<0.01 ;{ }^{* * *} p<0.001 ;$ and ns (nonsignificant) vs. HF. ${ }^{*} p<$ 0.001 vs. NC

\section{Saroglitazar attenuated the expression of} proinflammatory and profibrogenic mRNAs

We found a marked increase in hepatic mRNA expression of proinflammatory and pro-fibrogenic genes, including TNF $\alpha$, IL-6, MCP1, and TGF- $\beta$ in the qPCR analysis of gene expression in the HF group compared to the NC group ( $p<0.001$ for all, Fig. 2). Treatment with saroglitazar, fenofibrate, and pioglitazone significantly decreased the expression of proinflammatory genes $(p<0.001)$. The mRNAs level of TGF- $\beta$ as a fibrogenic mediator and MCP1 were increased 2.5-fold and 3.2- fold, respectively, following high-fat emulsion
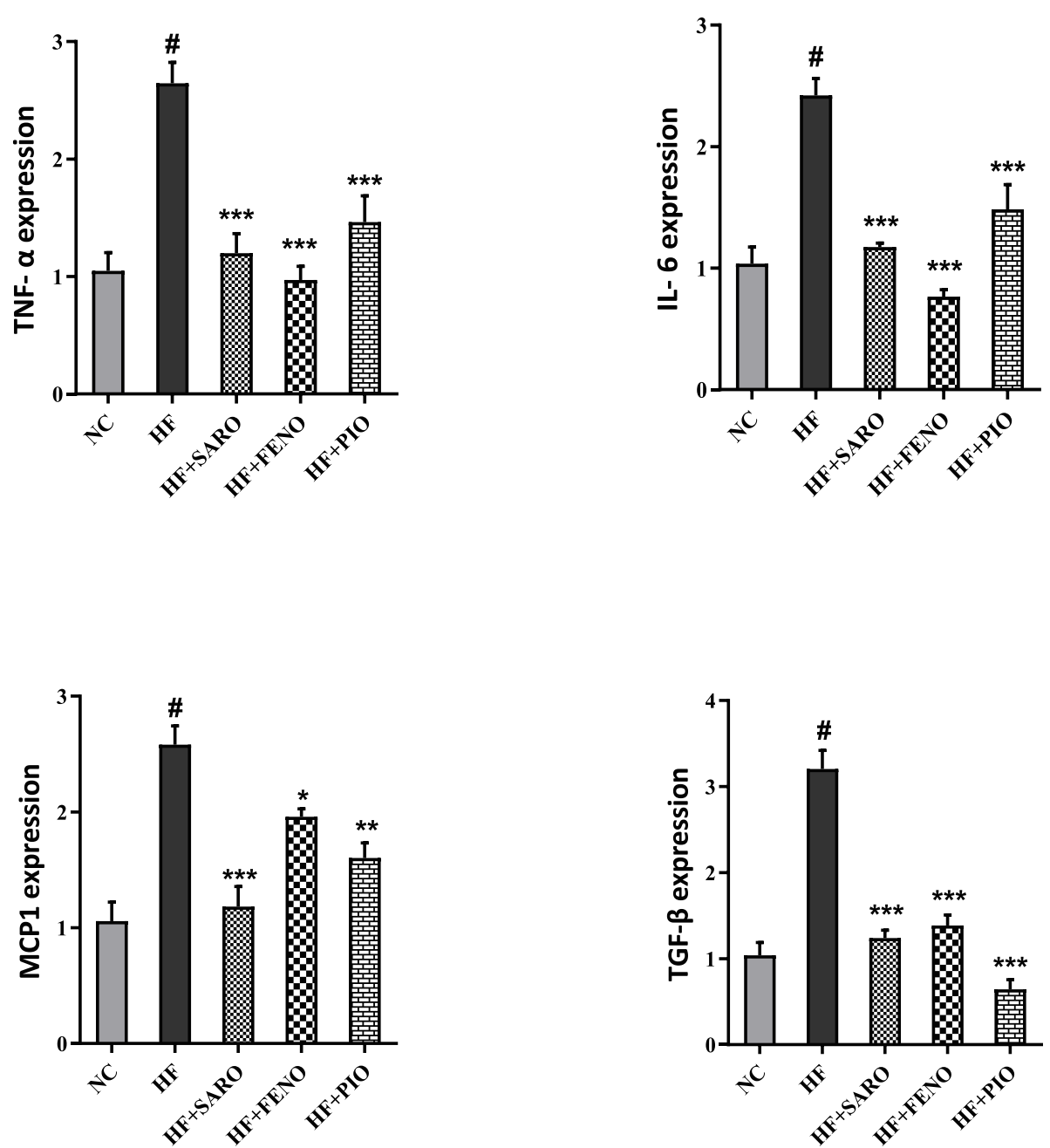

Fig. 2 Gene expression levels of proinflammatory cytokines and TGF- $\beta$ in response to treatment with PPAR agonists. Hepatic mRNA levels were determined using quantitative real-time PCR and normalized to $\beta$-actin mRNA expression. Values are expressed as the mean \pm S.D. of fold changes relative to the NC. Between-group, comparisons were tested by ANOVA followed by Tukey Kramer multiple comparisons test. TNF- $a$, tumor necrosis factor-alpha; IL-6, interleukin 6; MCP-1, monocyte chemoattractant protein 1; TGF- $\beta$, transforming growth factor-beta. ${ }^{*} p<0.05$; ${ }^{* *} p<0.01 ;{ }^{* * *} p<0.001$; and ns (nonsignificant) vs. HF. ${ }^{\#} p<0.001$ vs. NC 
feeding $(p<0.001)$. Our results showed that saroglitazar decreased the elevated MCP 1 mRNA more than fenofibrate and pioglitazone $(p<0.001$ vs. $p<0.05$ and $p<$ 0.01 , respectively). In addition, all the PPAR agonists could significantly decrease the upregulated mRNA of TGF- $\beta$ following the high-fat regime $(p<0.001)$. The effect of pioglitazone was the highest in this regard.

\section{Histopathological findings}

As illustrated in Fig. 3, microscopic examination of liver sections of rats in the HF group showed congestion, grade 3 hepatocellular steatosis, inflammation, and extensive fibrosis of stage 3 compared to the liver sections of the control rats with no indication of fat accumulation, inflammation, or fibrosis. These findings were confirmed by the H\&E staining and Masson's trichrome staining (Fig. 3, I and II, respectively). Saroglitazar administration for 6 weeks significantly improved fatty appearance, lobular inflammation, hepatocellular ballooning of liver tissue, and decreased fibrotic lesions. These parameters were also alleviated by fenofibrate and pioglitazone treatments comparable to saroglitazar administration (Fig. 3, I, II, and III). However, saroglitazar represented better scores in improving histopathological lesions than fenofibrate and pioglitazone (Fig. 3, III).

\section{Discussion}

The mechanism of development and progression of NAFLD/NASH is multifactorial and complex. According to the "two-hit hypothesis," the first event is fat accumulation in the liver. The second hit is activating inflammatory pathways, oxidative stress, and fibrogenesis [22]. Drugs that target the individual components of NASH pathogenesis have not been very effective so far. Efforts to find an ideal drug that can manage NASH's multifaceted condition have not been successful. Since PPAR- $\alpha$ and PPAR- $\gamma$ agonists can improve insulin resistance, liver steatosis, oxidative stress, inflammation, adipocytokines secretion, and fibrosis, saroglitazar as a dual PPAR- $\alpha / \gamma$ agonist, seems to be a rational choice in this condition. Our results showed that saroglitazar alleviated the NASH damages in our model better than fenofibrate and pioglitazone.

PPARs have crucial roles in regulating several biological processes associated with $\mathrm{NASH}$, including inflammation, lipid and glucose homeostasis, and fibrosis [23, 24]. Our results showed that treatments with all three PPAR agonists could significantly attenuate the increased inflammatory cytokines and TGF- $\beta$ as a fibrotic marker in our NASH model. As the primary mechanism, PPARs inhibit nuclear factor-kappa B (NF- $\mathrm{kB}$ ) activation and suppress its downstream inflammatory genes such as TNF- $\alpha$ and IL-6 [25]. TNF- $\alpha$ plays a pivotal role in

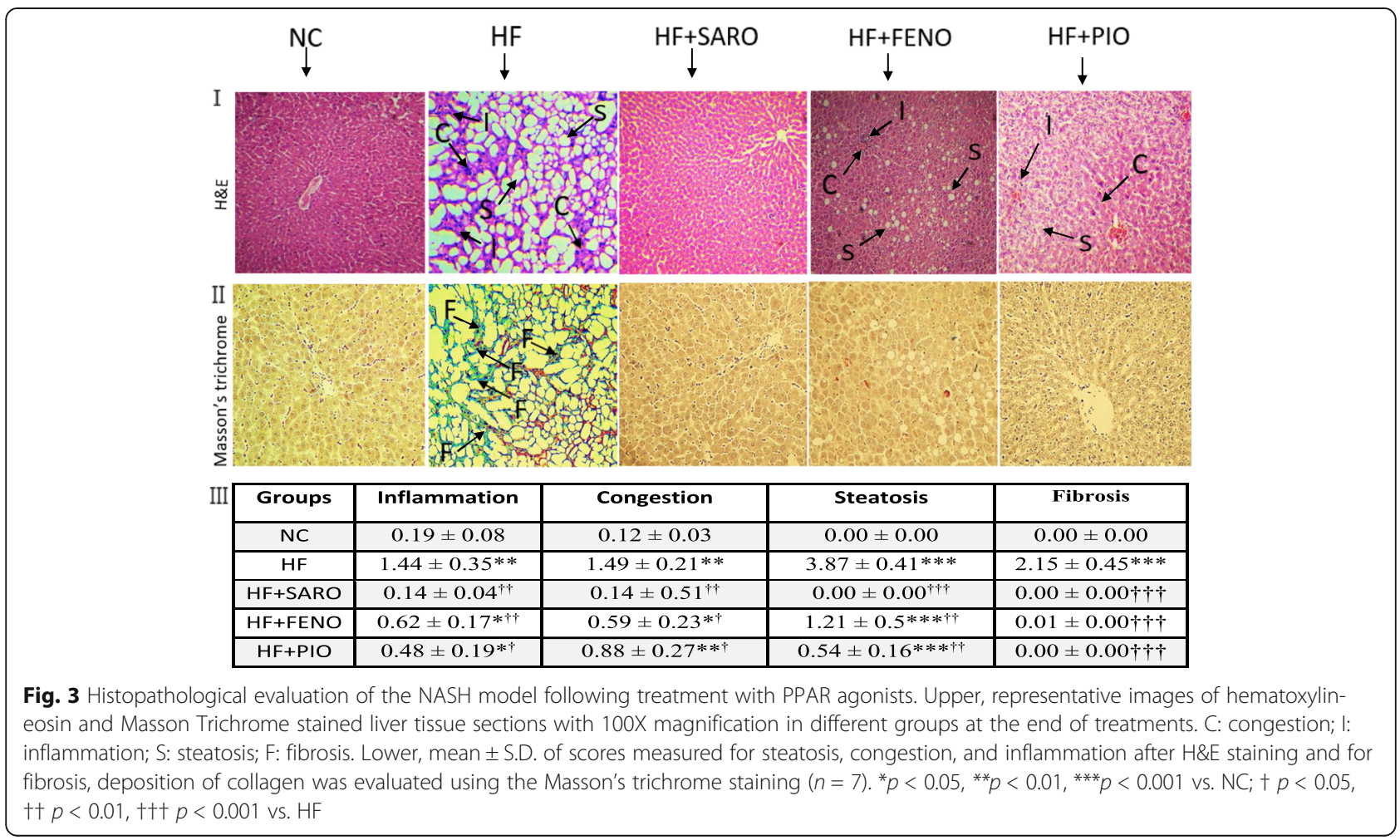


the progression of NAFLD to NASH through the induction of regulatory molecules associated with lipid and glucose metabolism, inflammatory cytokines, and fibrosis in the hepatocytes. TNF- $\alpha$ also directly induces MCP1 and TGF- $\beta$ expression as essential mediators in inflammation and fibrogenesis [10]. Earlier studies have shown PPAR $\gamma$ agonists to inhibit TNF- $\alpha$ and its associated cytokines. PPAR $\gamma$ agonists decreased TGF- $\beta$ in animal models of NASH and cholestatic fibrosis [26]. PPAR $\alpha$ and PPARY agonists have the potential to correct nonalcoholic steatohepatitis damages. Thus, co-activation of PPAR $\alpha$ and PPAR $\gamma$ using a dual PPAR $\alpha / \gamma$ agonist such as saroglitazar could be a reasonable approach to ameliorative NASH. In line with these findings recently Kumar et al. have demonstrated applying saroglitazar in a Diet induced animal model of NASH reduces hepatic ER stress, inflammation and fibrogenic signaling [27]. While it has been shown PPAR agonists differently affect inflammation and fibrosis, a fundamental question is how the new dual PPAR $\alpha / \gamma$ agonist is different from the more common $\alpha$ and $\gamma$ agonists, especially concerning the adipokines in relation to inflammation and fibrosis in the context of NASH, which has not been studied before. Here we compare modulating effects of saroglitazar with fenofibrate a PPAR $\alpha$ agonist and pioglitazone a PPAR $\gamma$ agonist. Our results confirmed that the dual PPAR $\alpha / \gamma$ agonist saroglitazar improved experimental NASH's biochemical and histopathological complications better than fenofibrate and pioglitazone.

Leptin and adiponectin are mainly secreted from adipose tissue and play essential roles in developing and progressing fatty liver disease. In obesity, leptin resistance augments the production and secretion of leptin [28]. Elevated leptin levels activate Kupffer cells and liver stellate cells, which give rise to the inflammatory processes in the liver [29], In contrast, adiponectin exerts anti-inflammatory properties in the liver and improves hepatic and peripheral insulin resistance. Adiponectin inhibits hepatic production of proinflammatory cytokines such as TNF- $\alpha$, IL- 6 by suppressing NF- $\mathrm{kB}$ activity [30]. To the best of our knowledge, this is the first study that suggested saroglitazar may exert its beneficial effects on hepatic steatosis through modulating leptin and adiponectin levels in the model of NASH.

Our findings confirmed that PPAR $\alpha$ and PPAR $\gamma$ activation favorably modified the adipokines by decreasing leptin and increasing adiponectin levels. In addition, PPAR- $\alpha$ activation can upregulate adiponectin receptor1 expression in visceral adipose tissue, which gives rise to enhanced adiponectin effects [18, 31]. Co-activation of PPAR $\alpha$ and PPAR $\gamma$ by saroglitazar treatment presented a better adipokine profile than fenofibrate and pioglitazone alone. It has been shown that correcting leptin and adiponectin levels can prevent profibrogenic responses by inhibiting TGF- $\beta$ in experimental models of NASH and chemicals-induced liver injury [32, 33]. Similarly, we showed that correcting the adipokines levels in response to PPAR agonists correlated well with improving the fibrosis scores at the end of treatments.

Adiponectin and TNF- $\alpha$ expression have a significant inverse correlation in adipose tissue. Injection of adiponectin suppressed TNF- $\alpha$ expression and reduced the plasma level of TNF- $\alpha$ that led to the prevention of fat accumulation and inflammation in several mouse models of chronic liver injury [34,35]. On the other hand, treatment with TNF- $\alpha$ suppressed the expression of adiponectin by inhibiting PPAR- $\gamma$ in adipocytes [36]. Therefore, adiponectin is known to act as a potent antiinflammatory and antifibrotic cytokine and a suitable target for treating steatohepatitis, while leptin exerts an inverse role [37-39]. Our results showed that saroglitazar effectively targeted adiponectin and leptin expression to suppress inflammatory and fibrogenic cytokines such as TNF- $\alpha$, IL-6, MCP1, and TGF- $\beta$ in the NASH model.

The H\&E and Masson's trichrome staining and Quantitative histopathological assessments showed strong antisteatotic and antifibrotic effects of saroglitazar. This effect was revealed by the disappearance of lipid droplets and collagen deposits in liver tissue. Separate PPAR $\alpha$ and PPAR $\gamma$ agonists could not provide the improvement provided by saroglitazar. This finding follows an earlier study that showed saroglitazar improved steatosis, while fenofibrate did not decrease hepatic lipid droplets in Zucker fa/fa rats [40]. In the present study, AST, and ALT as serum markers of NASH were significant reduced after 6 weeks of Saroglitazar treatment more pronounced as compared to fenofibrate or pioglitazone. These findings are consistent with clinical studies that were confirmed saroglitazar reduced the levels of these liver enzymes in patients with NAFLD and diabetic dyslipidemia [41, 42]. Fenofibrate, a selective PPAR $\alpha$ agonist, corrects hyperlipidemia by enhancing $\beta$-oxidation and causes a reduction in body weight. Pioglitazone is a synthetic PPAR $\gamma$ agonist used to lower blood glucose levels and lipotoxicity by modifying insulin resistance. Pioglitazone regulates the expression of lipid metabolism genes, stimulates glucose uptake in adipose tissue, and induces adipocyte differentiation [43]. However, since PPAR $\gamma$ agonists enhance the deposition of fatty acids and glucose rather than oxidation in the cell, there have been concerns regarding their side effects, such as body weight gain and clinical application in conditions such as the fatty liver. Treatment with pioglitazone in our study caused a significant increase in body weight following previous findings that treatment with TZDs is associated with body weight increase in obese animals and type 2 diabetic patients [41, 44-47]. In contrast, fenofibrate treatment completely normalized body weight 
compared to the HF group and increased the liver index, similar to the previous findings [48]. Co-treatment of fenofibrate and pioglitazone corrected the enlargement of the liver index [49]. Likewise, our results showed that saroglitazar treatment normalized body weight, liver weight, and liver index. Consistent with our findings, clinical studies also were demonstrated that taking Saroglitazar $4 \mathrm{mg}$ improved glycemic index, lipid profile, and weight loss in patients with NAFLD and type 2 diabetes $[41,42]$. Therefore, as documented by our results, the dual activation of PPAR $\alpha / \gamma$ is proposed to be more beneficial in NASH management.

In this study, we did not evaluate the protein expression of IL-6, TNF- $\alpha$, TGF- $\beta$, and MCP1 to confirm the mRNA expression of these molecules in the liver. However, this study primarily focused on the effects of saroglitazar on genetic and phenotypic features of NASH, which is supported by histopathological findings and the expression of inflammatory genes linked with NASH. We also evaluated circulating levels of leptin and adiponectin known as markers for the diagnosis and therapy in response to saroglitazar to demonstrate its antiinflammatory effects in the context of NASH. Our data will help drive future studies to identify molecular mechanisms by which saroglitazar improves NAFLD/ NASH.

\section{Conclusions}

Our results suggest that the dual activation of PPAR $\alpha$ and PPAR $\gamma$ by saroglitazar can effectively improve steatosis, fibrosis, and aspects of necro-inflammation in the HF-induced NASH model better than fenofibrate and pioglitazone. This approach may resolve drawbacks and side effects associated with the separate administration of PPAR $\alpha$ or PPAR $\gamma$ agonists.

\section{Abbreviations}

NAFLD: Non-alcoholic fatty liver disease; NASH: Non-alcoholic steatohepatitis: HF: High fat; PPARa: Peroxisome Proliferator-Activated Receptor a; PPAR

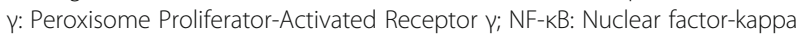
B; IL-6: Interleukin 6; TNF- a: Tumor necrosis factor alpha; TGF$\beta$ : Transforming growth factor beta; MCP-1: Monocyte chemoattractant protein 1; CMC: Carboxymethyl cellulose; SARO: Saroglitazar; PIO: Pioglitazone; FENO: Fenofibrate

\section{Acknowledgements}

The authors wish to thank the Ahvaz Jundishapur University of Medical Sciences for financial support of the study.

\section{Authors' contributions}

N.M., H.Y. and, M.T.J. designed the study. R. Ak. and T.B. performed all assays. R. Ak. and R.A. analyses the data. N. M wrote the first draft. H.Y. revised the manuscript. M.T.J. contributed to interpreting the results. The authors read and approved the final manuscript.

\section{Funding}

This study was supported by the Ahvaz Jundishapur University of Medical Sciences (Grant No. HLRC-0004). The funding source has no role in the design of the study, analysis, and interpretation of data, and publication of the manuscript.

\section{Availability of data and materials}

The datasets used and/or analyzed during the current study are available from the corresponding author on reasonable request.

\section{Declarations}

\section{Ethics approval and consent to participate}

Our study was approved by the Ethics Committee of Research Center \& Experimental Animal House, Ahvaz Jundishapur University of Medical Sciences. All experiments and methods were performed in accordance with relevant guidelines and regulations. Our study was performed according to ARRIVE guidelines.

\section{Consent for publication}

Not applicable.

\section{Competing interests}

The authors declare that they have no competing interests.

Received: 16 July 2021 Accepted: 20 September 2021

Published online: 01 October 2021

\section{References}

1. Younossi ZM, Loomba R, Rinella ME, Bugianesi E, Marchesini G, Neuschwander-Tetri BA, et al. Current and future therapeutic regimens for nonalcoholic fatty liver disease and nonalcoholic steatohepatitis. Hepatology. 2018;68(1):361-71. https://doi.org/10.1002/hep.29724.

2. Fang $Y-L$, Chen $H$, Wang $C-L$, Liang $L$. Pathogenesis of non-alcoholic fatty liver disease in children and adolescence: from "two hit theory" to "multiple hit model". World J Gastroenterol. 2018;24(27):2974. https://doi.org/10.3748/ wjg.v24.i27.2974.

3. Mota M, Banini BA, Cazanave SC, Sanyal AJ. Molecular mechanisms of lipotoxicity and glucotoxicity in nonalcoholic fatty liver disease. Metabolism. 2016;65(8):1049-61. https://doi.org/10.1016/j.metabol.2016.02.014.

4. Caligiuri A, Gentilini A, Marra F. Molecular pathogenesis of NASH. Int J Mol Sci. 2016;17(9):1575. https://doi.org/10.3390/ijms17091575.

5. Meek TH, Morton GJ. The role of leptin in diabetes: metabolic effects. Diabetologia. 2016;59(5):928-32. https://doi.org/10.1007/s00125-016-3898-3.

6. Kusminski CM, Scherer PE. Mitochondrial dysfunction in white adipose tissue. Trends Endocrinol Metab. 2012;23(9):435-43. https://doi.org/10.1016/j. tem.2012.06.004.

7. Polyzos SA, Aronis KN, Kountouras J, Raptis DD, Vasiloglou MF, Mantzoros CS. Circulating leptin in non-alcoholic fatty liver disease: a systematic review and meta-analysis. Springer. 2016. https://doi.org/10.1007/s00125-015-3 769-3.

8. Hotamisligil GS, Shargill NS, Spiegelman BM. Adipose expression of tumor necrosis factor-alpha: direct role in obesity-linked insulin resistance. Science. 1993;259(5091):87-91. https://doi.org/10.1126/science.7678183.

9. Montecucco F, Mach F. Does non-alcoholic fatty liver disease (NAFLD) increase cardiovascular risk? Endocr Metab Immune Disord Drug Targets (Formerly Current Drug Targets-Immune, Endocrine \& Metabolic Disorders). 2008;8(4):301-7 doi.org/10.2174/187153008786848268.

10. Kakino S, Ohki T, Nakayama H, Yuan X, Otabe S, Hashinaga T, et al. Pivotal role of TNF-a in the development and progression of nonalcoholic fatty liver disease in a murine model. Horm Metab Res. 2018;50(01):80-7. https:// doi.org/10.1055/s-0043-118666.

11. Selzner N, Selzner M, Odermatt B, Tian Y, van Rooijen N, Clavien PA. ICAM-1 triggers liver regeneration through leukocyte recruitment and Kupffer celldependent release of TNF-a/IL-6 in mice. Gastroenterology. 2003;124(3): 692-700. https://doi.org/10.1053/gast.2003.50098.

12. Douglas H. TGF- $\beta$ in wound healing: a review. J Wound Care. 2010;19(9): 403-6. https://doi.org/10.12968/jowc.2010.19.9.78235.

13. Braunersreuther V, Viviani GL, Mach F, Montecucco F. Role of cytokines and chemokines in non-alcoholic fatty liver disease. World J Gastroenterol: WJG. 2012;18(8):727. https://doi.org/10.3748/wjg.v18.i8.727.

14. Yu X, Dluz S, Graves DT, Zhang L, Antoniades HN, Hollander W, et al. Elevated expression of monocyte chemoattractant protein 1 by vascular smooth muscle cells in hypercholesterolemic primates. Proc Natl Acad Sci. 1992;89(15):6953-7. https://doi.org/10.1073/pnas.89.15.6953.

15. Kassel KM, Guo GL, Tawfik O, Luyendyk JP. Monocyte chemoattractant protein-1 deficiency does not affect steatosis or inflammation in livers of 
mice fed a methionine-choline-deficient diet. Lab Investig. 2010;90(12): 1794-804. https://doi.org/10.1038/labinvest.2010.143.

16. Brocker CN, Yue J, Kim D, Qu A, Bonzo JA, Gonzalez FJ. Hepatocyte-specific PPARA expression exclusively promotes agonist-induced cell proliferation without influence from nonparenchymal cells. Am J Physiol Gastrointest Liver Physiol. 2017;312(3):G283-G99. https://doi.org/10.1152/ajpgi.00205.201 6.

17. Moseti D, Regassa A, Kim W-K. Molecular regulation of adipogenesis and potential anti-adipogenic bioactive molecules. Int J Mol Sci. 2016;17(1):124. https://doi.org/10.3390/ijms17010124.

18. Tsuchida A, Yamauchi T, Takekawa S, Hada Y, Ito Y, Maki T, et al. Peroxisome proliferator-activated receptor (PPAR) a activation increases adiponectin receptors and reduces obesity-related inflammation in adipose tissue: comparison of activation of PPARa, PPARy, and their combination. Diabetes. 2005;54(12):3358-70. https://doi.org/10.2337/diabetes.54.12.3358.

19. Zou Y, Li J, Lu C, Wang J, Ge J, Huang Y, et al. High-fat emulsion-induced rat model of nonalcoholic steatohepatitis. Life Sci. 2006;79(11):1100-7. https://doi.org/10.1016/j.lfs.2006.03.021.

20. Kleiner DE, Brunt EM, Van Natta M, Behling C, Contos MJ, Cummings OW, et al. Design and validation of a histological scoring system for nonalcoholic fatty liver disease. Hepatology. 2005;41(6):1313-21. https://doi.org/10.1002/ hep.20701.

21. Liang W, Menke AL, Driessen A, Koek GH, Lindeman JH, Stoop R, et al. Establishment of a general NAFLD scoring system for rodent models and comparison to human liver pathology. PLoS One. 2014;9(12):e115922. https://doi.org/10.1371/journal.pone.0115922.

22. Buzzetti E, Pinzani M, Tsochatzis EA. The multiple-hit pathogenesis of nonalcoholic fatty liver disease (NAFLD). Metabolism. 2016;65(8):1038-48. https://doi.org/10.1016/j.metabol.2015.12.012.

23. Gross B, Pawlak M, Lefebvre P, Staels B. PPARs in obesity-induced T2DM, dyslipidaemia and NAFLD. Nat Rev Endocrinol. 2017;13(1):36. https://doi. org/10.1038/nrendo.2016.135.

24. Chen L, Li L, Chen J, Li L, Zheng Z, Ren J, et al. Oleoylethanolamide, an endogenous PPAR-a ligand, attenuates liver fibrosis targeting hepatic stellate cells. Oncotarget. 2015;6(40):42530. https://doi.org/10.18632/oncota rget.6466.

25. Delerive P, De Bosscher K, Besnard S, Berghe W, Peters JM, Gonzalez FJ, et al. Peroxisome proliferator-activated receptor a negatively regulates the vascular inflammatory gene response by negative cross-talk with transcription factors NF-kB and AP-1. J Biol Chem. 1999;274(45):32048-54. https://doi.org/10.1074/jbc.274.45.32048.

26. Wang L, Nan Y, Yuan X. Effect of rosiglitazone on the expression of tumor necrosis factor-a in the liver tissue of mice with non-alcoholic steatohepatitis; 2017.

27. Kumar DP, Caffrey R, Marioneaux J, Santhekadur PK, Bhat M, Alonso C, et al. The PPAR $a / y$ agonist saroglitazar improves insulin resistance and steatohepatitis in a diet induced animal model of nonalcoholic fatty liver disease. Sci Rep. 2020;10(1):1-14. https://doi.org/10.1038/s41598-020-66458z.

28. Chen Z, Yu R, Xiong Y, Du F, Zhu S. A vicious circle between insulin resistance and inflammation in nonalcoholic fatty liver disease. Lipids Health Dis. 2017;16(1):203. https://doi.org/10.1186/s12944-017-0572-9.

29. Wang J, Leclercq I, Brymora JM, Xu N. Ramezani-Moghadam M, London $\mathrm{RM}$, et al. Kupffer cells mediate leptin-induced liver fibrosis. Gastroenterology. 2009;137(2):713-23. e1. https://doi.org/10.1053/j.gastro.2 009.04.011.

30. Ouchi N, Walsh K. Adiponectin as an anti-inflammatory factor. Clin Chim Acta. 2007;380(1-2):24-30. https://doi.org/10.1016/j.cca.2007.01.026.

31. Haluzik M, Lacinova Z, Dolinkova M, Haluzikova D, Housa D, Horinek A, et al. Improvement of insulin sensitivity after peroxisome proliferator-activated receptor-a agonist treatment is accompanied by paradoxical increase of circulating resistin levels. Endocrinology. 2006;147(9):4517-24. https://doi. org/10.1210/en.2005-1624.

32. Ikejima $K$, Honda $H$, Yoshikawa M, Hirose M, Kitamura T, Takei $Y$, et al. Leptin augments inflammatory and profibrogenic responses in the murine liver induced by hepatotoxic chemicals. Hepatology. 2001;34(2):288-97. https:// doi.org/10.1053/jhep.2001.26518.

33. Walter R, Wanninger J, Bauer $S$, Eisinger $K$, Neumeier M, Weiss TS, et al. Adiponectin reduces connective tissue growth factor in human hepatocytes which is already induced in non-fibrotic non-alcoholic steatohepatitis. Exp Mol Pathol. 2011;91(3):740-4. https://doi.org/10.1016/j.yexmp.2011.09.006.
34. An L, Wang $X$, Cederbaum Al. Cytokines in alcoholic liver disease. Arch Toxicol. 2012;86(9):1337-48. https://doi.org/10.1007/s00204-012-0814-6.

35. Morris AM, Sennello JA, Fayad RA, Eckel RH, Dinarello CA, Fantuzzi G. T cellmediated hepatic inflammation modulates adiponectin levels in mice: role of tumor necrosis factor a. Metabolism. 2006;55(4):555-9. https://doi.org/1 0.1016/j.metabol.2005.11.008

36. Zhang B, Berger J, Hu E, Szalkowski D, White-Carrington S, Spiegelman BM, et al. Negative regulation of peroxisome proliferator-activated receptorgamma gene expression contributes to the antiadipogenic effects of tumor necrosis factor-alpha. Mol Endocrinol. 1996;10(11):1457-66. https://doi.org/1 0.1210/mend.10.11.8923470.

37. Kamada Y, Tamura S, Kiso S, Matsumoto H, Saji Y, Yoshida Y, et al. Enhanced carbon tetrachloride-induced liver fibrosis in mice lacking adiponectin. Gastroenterology. 2003;125(6):1796-807. https://doi.org/10.1053/j.gastro.2 003.08.029.

38. Koehler E, Swain J, Sanderson S, Krishnan A, Watt K, Charlton M. Growth hormone, dehydroepiandrosterone and adiponectin levels in non-alcoholic steatohepatitis: an endocrine signature for advanced fibrosis in obese patients. Liver Int. 2012;32(2):279-86. https://doi.org/10.1111/j.1478-3231.2 011.02637.x

39. Latif HA, Assal HS, Mahmoud M, Rasheed WI. Role of serum adiponectin level in the development of liver cirrhosis in patients with hepatitis $C$ virus. Clin Exp Med. 2011;11(2):123-9. https://doi.org/10.1007/s10238-010-0108-3.

40. Jain MR, Giri SR, Bhoi B, Trivedi C, Rath A, Rathod R, et al. Dual PPAR a/Y agonist Saroglitazar improves liver histopathology and biochemistry in experimental NASH models. Liver Int. 2018;38(6):1084-94. https://doi.org/1 $0.1111 /$ liv. 13634

41. Krishnappa M, Patil K, Parmar K, Trivedi P, Mody N, Shah C, et al. Effect of saroglitazar $2 \mathrm{mg}$ and $4 \mathrm{mg}$ on glycemic control, lipid profile and cardiovascular disease risk in patients with type 2 diabetes mellitus: a 56week, randomized, double blind, phase 3 study (PRESS XII study). Cardiovasc Diabetol. 2020;19(1):1-13. https://doi.org/10.1186/s12933-020-01073-w.

42. Goyal O, Nohria S, Goyal P, Kaur J, Sharma S, Sood A, et al. Saroglitazar in patients with non-alcoholic fatty liver disease and diabetic dyslipidemia: a prospective, observational, real world study. Sci Rep. 2020;10(1):1-9. https:// doi.org/10.1038/s41598-020-78342-x.

43. Haliakon S, Doare L, Foufelle F, Kergoat M, Guerre-Millo M, Berthault M-F, et al. Pioglitazone induces in vivo adipocyte differentiation in the obese Zucker fa/fa rat. Diabetes. 1997;46(9):1393-9. https://doi.org/10.2337/diab.46. 9.1393.

44. Boden G, Zhang M. Recent findings concerning thiazolidinediones in the treatment of diabetes. Expert Opin Investig Drugs. 2006;15(3):243-50. https://doi.org/10.1517/13543784.15.3.243.

45. de Souza CJ, Eckhardt M, Gagen K, Dong M, Chen W, Laurent D, et al. Effects of pioglitazone on adipose tissue remodeling within the setting of obesity and insulin resistance. Diabetes. 2001;50(8):1863-71. https://doi. org/10.2337/diabetes.50.8.1863.

46. Hermansen K, Mortensen LS. Bodyweight changes associated with antihyperglycaemic agents in type 2 diabetes mellitus. Drug Saf. 2007; 30(12):1127-42. https://doi.org/10.2165/00002018-200730120-00005.

47. Miyazaki Y, DeFronzo RA. Rosiglitazone and pioglitazone similarly improve insulin sensitivity and secretion, glucose tolerance and adipocytokines in type 2 diabetic patients. Diabetes Obes Metab. 2008;10(12):1204-11. https:// doi.org/10.1111/j.1463-1326.2008.00880.x.

48. Hoivik DJ, Qualls CW Jr, Mirabile RC, Cariello NF, Kimbrough CL, Colton HM, et al. Fibrates induce hepatic peroxisome and mitochondrial proliferation without overt evidence of cellular proliferation and oxidative stress in cynomolgus monkeys. Carcinogenesis. 2004;25(9):1757-69. https://doi.org/1 0.1093/carcin/bgh182.

49. Abd El-Haleim EA, Bahgat AK, Saleh S. Effects of combined PPAR- $\gamma$ and PPAR-a agonist therapy on fructose induced NASH in rats: Modulation of gene expression. Eur J Pharmacol. 2016;773:59-70. https://doi.org/10.1016/j. ejphar.2016.01.011.

\section{Publisher's Note}

Springer Nature remains neutral with regard to jurisdictional claims in published maps and institutional affiliations. 